\title{
Holistic Approach to The Environment and GMOs - The Case of Golden Rice
}

\author{
Ivica Kelam ${ }^{1}$
}

${ }^{1}$ Assistant Professor at Faculty of Education/Josip Juraj Strossmayer University of Osijek, Croatia; Head of the Croatia Osijek Unit of UNESCO Chair in Bioethics (Haifa); Head of the Centre of Integrative Bioethics at Josip Juraj Strossmayer University of Osijek; Head of the Department of Philosophy and History/Faculty of Education.

Corresponding Author: Ivica Kelam

E-mail:kelamivica@gmail.com

\begin{abstract}
This paper aims to point out the fundamental differences between supporters and opponents of genetic modification technology by using a brief analysis of the development and controversy that surrounds the genetically modified golden rice. Supporters present golden rice like a typical example of the benefits of genetic modification technology and, at the same time, accuse opponents of delaying commercial planting. Opponents from the very beginning point to the problem of golden rice as a partial quick fix of vitamin A deficiency, whereby the complexity of the problem of vitamin A deficiency in the diet of the population of underdeveloped countries is ignored. Today, 19 years after the presentation of golden rice in the media, this technology is still not ready for commercial use, not because of opposition by Greenpeace and other opponents, but because of the elementary fact that introducing genetically modified plants into a living environment is a challenge that science cannot yet adequately respond. In this paper on the golden rice example, we will point out the importance of the holistic approach to the environment taking in a count the complexity and unpredictability of introducing new biotechnological inventions into the environment
\end{abstract}

Keywords: Biotech industry, golden rice, Greenpeace, vitamin A deficiency, environment.

\section{INTRODUCTION}

For the development and successful implementation of genetically modified crops, public support is one of the critical elements. From the very beginning, sowing genetically modified crops has caused controversy in public, golden rice has presented in addition to its health properties as an example of the benefits and usefulness of genetic modification technology. Environmental NGOs like Greenpeace argue that golden rice is not a solution to the problem of vitamin A deficiency, but a means of imposing unwanted technology on the suspicious public. The saga about golden rice has lasted for 19 years, and during that period there have been exchanged serious accusations between opponents and supporters, ranging from the introduction of corporate dictatorship by opponents to supporter's accusations of the Holocaust for preventing the introduction of golden rice into the diet. In the paper, through a brief analysis of the history of development and controversy over golden rice, particular emphasis will be placed on the lack of research into the 
environmental and social impact of golden rice, from which it is evident that, despite its noble intention, it remains only an unfulfilled dream of its creators.

\section{Golden rice - a brief overview of development and some ethical issues}

Ingo Potrykus, a professor at the Swiss Federal Institute of Technology, appeared on the cover of Time Magazine with the headline 'This rice could save a million children a year' [1]. The article describes Potrykus' creation of genetically modified rice enriched with carotene, which he claims could save children in undeveloped countries from blindness and death. The Golden Rice project started back in the 1980s. In August 2012, Greenpeace issued a press release informing the public of a study published in a scientific journal describing the experiment of feeding genetically modified rice to 24 Chinese children between the ages of 6 and 8 [2]. Greenpeace argued that the said study, supported by the United States Department of Agriculture, could not have been conducted without violating the postulates of scientific and medical ethics. A Greenpeace spokesman for East Asia, responding to this news, said: 'It is incredibly disturbing to think that the US research body used Chinese children as guinea pigs for genetically modified food, despite a clear directive against this experiment issued by Chinese authorities in 2008' [2].

A controversial study, $\beta$-Carotene in Golden Rice is as good as b-carotene in oil at providing vitamin $A$ to children referenced by Greenpeace evaluated the efficacy of bio-conversion of $\beta$-carotene to vitamin A in children who were fed golden rice [3]. The paper detailed that research groups from Tufts University led by Tang, the Chinese Center for Disease Control and Prevention, and other scientific research institutions selected 72 healthy 6- 8 year-old children in Hunan, China; divided them into three groups; and provided 24 children with $60 \mathrm{~g}$ of Golden Rice for 21 days while drawing their blood to measure the vitamin A concentrations. The results showed that the effect of the Golden Rice was as good as that of vitamin A capsules. So far this was the only scientific study conducted to determine the impact of consumption of gold rice on human health, which is why it was so media-covered and used as a key argument about the justification of the whole golden rice project. Golden rice promoters used this study for media purposes, constantly emphasizing the justification for introducing golden rice to the fields as quickly as possible. However, after three years, on July 29, 2015, the publisher unexpectedly withdrew the article, stating ethical reasons [4].

The $\mathrm{Yu}$ and Li addressed this problem in their paper Informed Consent and Ethical Review in Chinese Human Experimentation: Reflections on the 'Golden Rice Event,' according to them, Tang et all. did not provide sufficient evidence that a local ethics committee approved the study in China in a manner that is entirely consistent with the guidelines of the National Institutes of Health. Moreover, $\mathrm{Yu}$ and Li claim that the project also concealed from the Chinese ethics committee and the informed consent process the fact that genetically modified rice was to be used in the trial, which violated the ethical review requirements [5]. Violations of ethical principles and lack of informed consent have also been highlighted in an article published in Nature where it stated, none of the children, their parents or school teachers were aware that Golden Rice was involved, according to a 45minute investigative news program broadcast on 8 December on CCTV, China's state television channel. The informed-consent form said that the rice contained $\beta$-carotene, but not that it was genetically modified or that it was Golden Rice. Nor did it highlight uncertainty around any potential risks of ingesting such rice...

Moreover, Wang didn't apply for ethical evaluation of the trial, instead fabricating the approval documents, according to CDC. And Tang brought Golden Rice from the United States to China illegally, without due declaration to the relevant Chinese authorities [6].

As is evident from this affair, the key problem is not a question of safety of human consumption of golden rice, but the lack of transparency and informed consent of all participants, including children and their parents, who have not been informed at all that their children will be consuming genetically modified golden rice. This affair has taught us that it is critical in any future studies to pay close attention to strict adherence to ethical guidelines and to obtain informed consent from 
all participants. Following the withdrawal of the study, in June 2016, a group of 107 Nobel laureates in an open letter published in major world newspaper such as The Washington Post blamed opponents of GMOs, most notably Greenpeace, for the deaths of millions of children and adults in developing countries around the world [6]. The petition has attracted a great deal of public attention, as biotechnology promoters have used this open letter to attempt once again to impose on the public the necessity of implementing genetically modified crops as quickly as possible.

Wilhelmina Peregrine, campaigner at Greenpeace Southeast Asia in response to this open letter highlights the following: „Accusations that anyone is blocking genetically engineered 'Golden' rice are false. 'Golden' rice has failed as a solution and is not currently available for sale, even after more than 20 years of research. As admitted by the International Rice Research Institute, it has not been proven actually to address Vitamin A Deficiency. So, to be clear, we are talking about something that does not even exist. Corporations are overhyping 'Golden' Rice to pave the way for global approval of other more profitable genetically engineered crops. This costly experiment has failed to produce results for the last 20 years and diverted attention from methods that already work. Rather than invest in this overpriced public relations exercise, we need to address malnutrition through a more diverse diet, equitable access to food and eco-agriculture" [6].

To understand the controversy over golden rice, we need to look at some facts. More than half of the world's population eats rice daily since rice is the basis of their daily diet. Rice is a poor source of many essential micro-elements and vitamins. In Southeast Asia, $70 \%$ of children under the age of 5 suffer from vitamin A deficiency, leading to increased susceptibility to various diseases and vision problems, which in severe cases leads to blindness. According to UNICEF forecasts, increasing dietary intake of Vitamin A could prevent the premature death of between 1 and 2 million children between the ages of 1 and 4 years [7]. Proponents argue that there is no alternative to golden rice to combat vitamin A deficiency and blame government agencies and critics for endangering the lives of millions of children, like the appeal of Adrian Dubock who calculated that 50,000 children become blind every month due to the delay in bringing golden rice on the market [8]. Other proponents claim that the government agencies and NGOs are participants in the Holocaust against the underprivileged children of the global South [9]. Furthermore, to accelerate the marketing of golden rice and reduce development costs, proponents require a general reduction in risk assessment standards for genetically modified plants [10].

For delaying the commencement of commercial planting of golden rice proponents held accountable excessive state regulation and a relentless campaign of anti-GMO activists and organizations such as Greenpeace. Bjørn Lomborg, author of the book The Skeptical Environmentalists, wrote an article on February 2013 stating that the commercial sowing of golden rice has been delayed for 12 years because of relentless opposition to GM foods by rich, wellmeaning residents of the global in the West, while around 8 million children worldwide died of vitamin A deficiency [11]. Lomborg wants to exert pressure on the public and regulatory agencies to extricate the uncontrolled introduction of genetically modified crops into the fields by overstating the deaths of children due to vitamin A deficiency. Lomborg forgets the elemental biological fact, as pointed out in a Science article, which points out that the long way "lies before the commercial sowing of golden rice, in the process of crossing golden rice with Indica rice varieties, which are most popular among farmers and consumers across Asia [12]. Golden rice critics such as nutritionist Marion Nestle, on the other hand, state: „This rice, although not yet available commercially, has become the poster child of the food biotechnology industry's extensive public relations campaign to convince the public that the benefits of genetically engineered agricultural products outweigh any safety, environmental, or social risks they might pose.

National magazines promote golden rice as a means to prevent the more than one million annual deaths and cases of blindness that occur among children in developing countries as a result of vitamin A deficiency. The creation of golden rice appears to confirm the belief that biotechnology is the key to solving world food and nutrition problems. Consideration of basic principles of nutrition suggests that rice containing $\tilde{\mathrm{A}} \ddot{\mathrm{Y}}$-carotene is unlikely to alleviate vitamin A deficiency. 
To begin with, the bioavailability of $\tilde{\mathrm{A}} \ddot{\mathrm{Y}}$-carotene is quite low- $10 \%$ or less by some estimates. To be active, $\tilde{\mathrm{A}} \ddot{\mathrm{Y}}$-carotene--a pro-vitamin--must be split by an enzyme in the intestinal mucosa or liver into two molecules of vitamin A. Like vitamin A, the pro-vitamin is fat-soluble and requires dietary fat for absorption. Thus, digestion, absorption, and transport of $\tilde{\mathrm{A}} \ddot{Y}$-carotene require a functional digestive tract, adequate protein and fat stores, and adequate energy, protein, and fat in the diet. Many children exhibiting symptoms of vitamin A deficiency, however, suffer from generalized protein-energy malnutrition and intestinal infections that interfere with the absorption of $\tilde{A} \ddot{Y}$ carotene or its conversion to vitamin A. The complexity of the physiological, nutritional, and cultural factors that affect vitamin A status suggest that no single-nutrient added to food can be effective as a remedy for dietary deficiencies. Instead, a combination of supplementation, fortification, and dietary approaches is likely to be needed, along with a substantial commitment to improving socioeconomic status. Food biotechnology may yet lead to products that improve nutrition and health, but at the moment, its benefits remain theoretical [13].

Vandana Shiva argues that golden rice is not a solution to the problem of vitamin A deficiency since the first generation of golden rice contains an insufficient amount of vitamin A. Recommended daily dose of vitamin A for an adult to be obtained, according to Vandana Shiva's calculation, should eat 2,272 kilos of dry rice daily, which is, of course, impossible to achieve. According to her, the solution is not to genetically modify rice, but to allow people to diversify their diet, since many plants that grow in these parts of the world have a much higher percentage of vitamin A in them. Bengal women use more than 200 species of different plants in their diet, and more than 3 million people in Bangladesh, thanks to growing vitamin A-rich vegetables in their garden, have eliminated the risk of blindness [14]. Peter Rosset argues that golden rice does not solve the problem of vitamin A deficiency: 'If one reflects upon patterns of development and nutrition one must quickly realize that Vitamin A deficiency is not best characterized as a problem, but rather as a symptom, a warning sign if you will'. It warns us of broader dietary inadequacies associated with both poverty and with the agricultural change from diverse cropping systems toward rice monoculture. People do not present with Vitamin A deficiency because rice contains too little Vitamin A or beta-carotene, but rather because their diet has been reduced to rice and almost nothing else, and they suffer many other dietary illnesses that cannot be addressed by betacarotene, but which could be addressed, together with Vitamin A deficiency, by a more varied diet. A magic-bullet solution which places beta-carotene into rice-with potential health and ecological hazards-while leaving poverty, poor diets, and extensive monoculture intact, is unlikely to make any durable contribution to well-being [15].

Scientific studies have shown that the prevalence of vitamin A deficiency in underdeveloped countries has decreased significantly over time, as the following data show. In 1991, 39\% of children aged 6-59 months in low-income and middle-income countries were vitamin A deficient. In 2013, the prevalence of deficiency was $29 \%$. Vitamin A deficiency significantly declined in the east, and southeast Asia and Oceania from 42\% to 6\%, a decline in Latin America and the Caribbean from $21 \%$ to $11 \%$ also occurred. In 2013, the prevalence of deficiency was highest in sub-Saharan Africa 48\%, and South Asia 44\%, 94, 500 deaths from diarrhea and 11, 200 deaths from measles were attributable to vitamin A deficiency in 2013, which accounted for 7\% of all deaths in children younger than five years in low income and middle-income countries. More than 95\% of these deaths occurred in sub-Saharan Africa and South Asia [16]. On the other hand, golden rice proponents, deny Vandana Shiva's allegations, pointing out that the new generation of golden rice contains a much higher concentration of beta-carotene, and, according to calculations, the daily consumption of one bowl of golden rice per person would significantly reduce vitamin A deficiency [17].

According to Swamy, the second generation of golden rice event GR2E could produce enough beta-carotene, or pro-vitamin A, to help those who suffer from vitamin A deficiency. According to the study "Mean pro-vitamin A concentrations in milled rice of GR2E [golden rice] can contribute up to 89-113 percent and 57-99 percent of the estimated average requirement for vitamin A for preschool children in Bangladesh and the Philippines, respectively" [18]. Although the 
findings of this study look impressive, when analyzing the paper, it turns out that when they harvested the golden rice, the researchers then froze the grain until it was tested for its pro-vitamin A levels. They did not store it under normal conditions or cook it - two fundamental things that ordinarily happen to rice when it is marketed and consumed. That is very important to keep in mind because as Bollinedi and group points out in another recent study, storage massively reduces the beta carotene (or pro-vitamin A) content of golden rice. They showed that after just six months of storage in the presence of air, even at the low refrigerated temperature of 4 degrees $C$, the betacarotene degraded by around $68-79 \%$. Moreover, normally, rice would not, of course, be stored at 4 degrees C, let alone frozen. Cooking also degraded the beta-carotene by up to $24 \%$ [19]. They concluded that the best way to preserve the beta-carotene content of the GM golden rice was to vacuum pack it as paddy (though no one eats paddy). Under these conditions, at 25 degrees $C$, just over half (54\%) of the beta-carotene was retained, versus only around $20 \%$ under non-vacuum packaging (air packaging) at the same temperature [19].

Swamy and his group are aware of this issue, and point out in the conclusion of their study, 'Practically, nutritional effects will be significantly influenced by substitution rates of conventional rice with rice containing event GR2E, varietal (background germplasm) effects on provitamin A expression, actual bioconversion efficiency in target populations, and the known loss of $\beta$-carotene over time due to storage, processing, and cooking methods' [18]. As can be seen from the studies cited, there are still many obstacles to commercial sowing and the successful consumption of golden rice. The problem of declining beta-carotene in golden rice confirms once again the doubts of opponents of golden rice. Moreover, the US Food and Drug Administration's recommended daily allowance of vitamin A for an adult woman is $700 \mu \mathrm{g}$ (micrograms), and for an adult man is even more $900 \mu \mathrm{g}$ [20]. According to FDA recommendations, adult men should eat 175 grams of golden rice daily. Ultimately, this means they should be overeating golden rice to meet their daily allowance of vitamin A. I will end this chapter with an interesting 2018 FDA opinion.

The US Food and Drug Administration (FDA) concluded its consultation process on GM golden rice by informing its current developers, the International Rice Research Institute (IRRI) that the concentration of $\beta$-carotene in GR2E rice is too low to warrant a nutrient content claim [21].

\section{Examples of potentially harmful effects of relations environment-golden rice:}

\section{Lower yield issue}

Despite the increased concentration of beta-carotene in new generations of golden rice, it should be noted that after more than 25 years of research and tens of millions of dollars spent on development, golden rice is not yet ready for commercial sowing, despite years of experimental planting conducted by the International Rice Research Institute (IRRI) in the Philippines. Moreover, experimental planting done by the IRRI has shown that golden rice has a lower yield than conventional rice varieties. The IRRI published on its website a statement on the results of field trials on the crop: Preliminary results were mixed. While the target level of beta-carotene in the grain was attained, average yield was, unfortunately, lower than that from comparable local varieties already preferred by farmers [22].

Furthermore, in a study published in 2017, Indian researchers found that golden rice genes had unwanted side effects. When they introduced the golden rice genes into their high yielding and agronomically superior variety of indica rice, it turned pale and stunted, the flowering was delayed, and the roots grew abnormally. The yields were so reduced that it was not suitable for cultivation [23].

The study's authors identified several reasons for the unexpected effects - the new gene constructs interfered with the plant's gene for producing growth hormones, and the additional gene constructs were not, as intended, active solely in the kernels, but also in the leaves, resulted in a substantial reduction in the content of chlorophyll that is essential for vital functions in the plants. These unintended effects were not detected in previous investigations, and it was assumed that the genetically engineered plants used in these trials would show genetic stability. But these 
detrimental genomic effects remained undetected until the transgenic plants were crossed with the variety called Swarna, which is grown widely in India [24]. Why this is happening is best described by Dr Michael Antoniou: "I have always asserted that the GM transformation process as used in the development of GMO crops selects for the insertion of the GM gene into active regions of the genome (areas where plant host genes are switched on and functioning). This bias in the GM gene insertion into active regions, therefore, maximizes the possibility of disrupting the function of one or more host genes, with potentially adverse effects such as poor crop performance or even toxicity. This latest finding of the GM gene insertion into a vital host gene in the golden rice is a graphic illustration of this principle. If the developers of golden rice had conducted a proper molecular characterization of this GM event at the time it was generated, they would have identified the host gene disruption that led to the stunted and deformed growth of the rice plants. Then they could potentially have avoided this negative outcome at such a late stage in the development and release of golden rice. Now it's back to square one, with years of research work and millions of dollars wasted" [25].

\section{Issues with cross-fertilization and unintended changes in the genome of plants}

Another big problem is the possible negative impact on the environment through cross-fertilization with wild rice. Studies confirm that hybrids are resulting from cross-fertilization exhibit unexpected biological characteristics, such as better features in the vegetative and reproductive stages, longer stems, more shoots, and sprouts per plant [26]. These effects can cause the uncontrolled spread of these hybrid plants in the environment. Researchers remain surprised by the improved ability of plants, as specific alterations cannot explain these changes to the genome of the plant achieved through genetic engineering. Scientists have a minimal ability to predict the proliferation potential and biological characteristics of transgenic rice and its hybrids. Another problem is that, when switching to local rice varieties, significant fluctuations in the vitamin A content of rice can occur. The genetically modified construction is not always transferred reliably from the original genetically modified rice plant to the next generation [27]. Experts point out that the cross-breeding of plants results in a higher number of genes altering activity, whereas it does not occur in transgenesis (see, for example, [28], [29]).

Changes in the activity of genes are widespread in the processes of plant breeding. Plants also respond naturally to environmental conditions by adjusting their gene activity. Reproduction and growth can also cause activity that leads to many altered genes at the same time. However, the number of changed genes is not of great importance since certain segments of DNA are entirely under the control of the complex mechanisms of natural gene regulation, and flexible system that responds to changes in conditions in a way that synchronizes the activity of genes. In the process of genetic modification of plants, natural mechanisms of gene regulation are not used. Moreover, they are deliberately circumvented. In a genetically modified plant, the action of inserted genes regulated promoters that are not susceptible to general gene regulation in plants and that regulate the expression of inserted genes. The result is that genetically modified plants cannot control this new metabolic pathway. Some plants respond to the introduction of foreign genes by excluding or deactivating newly inserted genes; this phenomenon is called gene silencing. Plants use this natural defense mechanism, which serves them as a defense against viral DNA contamination [30].

Therefore, promoters that forcibly activate genetically modified inserted genes are used to prevent inactivation of the inserted genetically modified genetic construct and to ensure its natural expression. We can conclude that scientists are trying to use genetic engineering to reprogram plants. Conversely, conventional plant breeding uses the natural genetic potential in plants and their gene regulation system. This distinction is fundamental both to clarify health risks and to evaluate the consequences of entering the transgene in ecosystems and gene pool of wild and cultivated plants. Any changes in the expression of native genes in a plant caused by the insertion of additionally inserted genes should always be carefully examined, as this may be an indicator of disturbance in the normal gene regulation system.

Since the insertion of a gene into a genetically modified plant, despite claims by proponents, is not a precise process, it can be expected that the genetically modified genes will be implemented at a disadvantageous position in the plant genome and lead to a pleiotropic effect (when the gene affects 
several traits simultaneously). Genetic intervention as a result of the insertion of a genetically modified gene into a plant can result in a range of biological effects that are relevant for risk assessment. Possible reactions include general weakening of the plant such as increased susceptibility to disease, lower yields, decreased plant tolerance to stress such as climatic conditions, but also improved plant ability through, for example, increased the production of pollen and seeds or production of unwanted, anti-nutritional, immunogenic or toxic components. For example, in golden rice, there is an unintended change in the composition of the carotenoids in the rice stem [31].

Newly inserted genes are active throughout the plant, not only in the grain, for example, and so they interact with components in other parts of the plant. For now, it is unclear what effect this has on the golden rice plant as a whole. Critics fear that certain environmental conditions may cause adverse reactions in genetically modified plants, or that such unplanned and possibly harmful reactions will occur after sowing several successive generations of plants. It is interesting to note that systematic studies on the interaction of genetically modified plants and their environment are not currently required as part of the process for authorizing the sowing of genetically modified plants in the EU. However, it should be noted that there is a growing body of scientific research dealing with the occurrence of undesirable traits in genetically modified plants such as petunia [32], cotton and maize [33], potatoes [34], wheat [35] and soybeans [36]. The research mentioned above clearly demonstrates the necessity of such research to evaluate the environmental impact of genetically modified plants. The study of genetically modified wheat showed that, unlike plants from greenhouses that do not show unexpected reactions, wheat plants that are grown on the experimental field had significantly lower yields and have shown higher rates of infection with the highly toxic ergot fungi. This research clearly shows us how relevant these questions are for risk assessment [37].

Therefore, Zeller in their research require studies of the environmental behavior of genetically modified plants. Furthermore, [38] they recommend the introduction of stress tests in their research. In the process of deciding on the release of genetically modified golden rice in the environment, we should be aware of the following facts. In regions where future sowing of golden rice is planned, there is a weed rice (a type of wild rice classified and treated as weed) with which golden rice can easily cross pollen and thus insert modified genes into weed rice. Wild rice species are widespread in many agricultural regions [39] [40]. Genetic crossing between cultivated rice fields and wild varieties that grow in an environment often occurs [40]. In such circumstances, it is difficult to prevent the uncontrolled spread into the environment of genotypes whose natural regulation of genes has been modified by the technical application. There is a real possibility that genetically modified genes can spread and accumulate in weed rice [40]. Research done in China shows that hybrids resulting from cross-breeding between genetically modified rice and its wild relatives may show unexpected biological characteristics. For example, the concentration of Bt toxin in genetically modified rice, which is deadly to insects and therefore serves as an insecticide in agriculture, has been significantly increased in some plants that have resulted from the crossfertilization of plants genetically modified rice and the wild rice varieties [41].

Furthermore, these hybrid plants had improved biological capabilities compared to non-transgenic parent plants [42], and this may lead to an increased spread of these plants in the future. The improved ability of hybrid plants was unexpected, and scientists cannot explain the specific changes that have occurred as a result of the genetic modification of the plant. Scientists are limited in their ability to predict the potential for uncontrolled spread and biological features of genetically modified rice and its cross-breeds. In any case, it seems unlikely that foreign genetically modified genes, once spread among the wild population, can be restricted or returned to the laboratory (see [43]). Recent research shows that future climate change will cause genetically modified genes to move even faster and easier into the rice weed population [44]. Simple cross-breeding features of genetically modified rice can remain inactive for a long time, and that is why it poses a threat to the ecosystem and can cause serious difficulties in the cultivation of rice in general. For example, that future generations will cross-breed and contaminate the environment with genetically 
modified genes. Genetic exchange is not a one-way street, and it goes both ways. The exchange of genes between cultivated conventional rice fields and the surrounding varieties of wild rice is a common phenomenon. The same rule applies to genetically modified rice. Pollen of wild rice varieties can potentially take genetically modified genes in case of their mutual cross-breeding, back in the field - even in fields where conventional rice is grown.

Thus, the cultivation of golden rice potentially threatens to cause unpredictable and extremely problematic scenarios by leaps.

1. Potentially there is a cross-breeding of genetically modified varieties of rice crops and their wild relatives, which can exhibit remarkable biological properties that can be rapidly expanded into the environment, with unpredictable environmental consequences.

2. Once genetically modified foreign genes are mixed with wild rice populations, it is no longer possible to control, limit, or reverse their spread.

3. Besides, one should be aware that as the genetically modified foreign genes spread in the population of wild rice, contamination of conventional rice crops is inevitable, and what it means for the security of supply of food should not be emphasized.

We can conclude that in the case of future commercial planting of golden rice it is necessary to adhere to the guidelines outlined in the work of Bauer-Panskusa and associates point out the following: The possibility of eliminating genetically modified plants should be a prerequisite for their use. The medium and long-term effects of their release on evolutionary processes, biodiversity, and human health cannot be scientifically predicted with the appropriate degree of certainty. The release of genetically modified crops into the environment can only be accepted if the length and location of the release can be controlled (see [45]). We conclude that if these guidelines were followed in the assessment of the authorization to plant genetically modified golden rice, sowing would be prohibited.

\section{CONCLUSION}

The case of golden rice has caused controversy and public attention for 19 years. The tremendous promise of saving millions of children from blindness and death due to planting and consumption of golden rice has not been fulfilled. Golden rice proponents blame opponents of biotechnology, led by Greenpeace, and strict regulatory rules for the commercial delay in golden rice commercial sowing. As seen in the paper, the truth is much simpler. Due to its complexity and problems encountered, from reduced yields, through the volatility of the amount of beta-carotene in the rice itself, to the possibility of genetic contamination through cross-breeding with rice weeds, golden rice is still not commercially sown, and it is very doubtful whether it will ever be ready for commercial sowing. The failure of successful cultivation of golden rice, once again, confirms how difficult it is for a trait that has been successfully genetically modified and implemented into a plant in the laboratory to convey into the environment and the real world without a multitude of potentially harmful and unwanted side effects. The golden rice saga confirms the views of critics on the myriad of unknowns surrounding this technology, and it is only reasonable in the development and eventual sowing of golden rice to adhere strictly to the precautionary principle, since, as research shows, irreversible environmental damage can and potentially will occur.

\section{REFERENCES}

1. Nash JM. This rice could save a million kids a year. Time Magazine. 2000 Jul 31;31.

2. James C. Global status of commercialized biotech/GM crops, 2011. Ithaca, NY: ISAAA; 2011.

3. Tang G, Qin J, Dolnikowski GG, Russell RM, Grusak MA. Golden Rice is an effective source of vitamin A. Am J Clin Nutrition 2009;89(6):1776-83.

4. Lee H, Krimsky S. The arrested development of Golden Rice: the scientific and social challenges of a transgenic biofortified crop. Int J Soc Sci Stud 2016;4:51.

5. Yu X, Li W. Informed consent and ethical review in Chinese human experimentation: reflections on the "Golden Rice Event". Biotechnol Law Report 2014;33(4):155-60. 
6. Qiu J. China sacks officials over Golden Rice controversy. Nature 2012,Dec 10.

7. Achenbach J. 107 Nobel laureates sign letter blasting Greenpeace over GMOs. Washington Post. 2016 Jun 30;30.

8. ML Guerinot, The Green Revolution Strikes Gold (ed. D Castle; M Ruse). Genetically Modified Foods, Prometheus Books, New York. 2002; pp41-4.

9. D Castle, Ruse M. Genetically Modified Foods. Prometheus Books, New York. 2002; pp52.

10. Chassy BM. Food safety risks and consumer health. New Biotechnology 2010;27(5):534-44.

11. Potrykus I. Regulation must be revolutionized. Nature 2010;466(7306):561-2.

12. Lomborg B. The deadly opposition to genetically modified food. Slate.

13. Enserink M. Tough lessons from golden rice.

14. Nestle M, Greger JL. Genetically engineered" golden" rice unlikely to overcome vitamin A deficiency/Response. J Acad Nutr Diet 2001;101(3):289-96.

15. Scott D. The technological fix criticisms and the agricultural biotechnology debate. J Agricult Environ Ethics 2011;24(3):207-26.

16. Rosset P. Genetically modified crops for a hungry world: How useful are they really. Tailoring Biotechnologies 2006;2(1):79-94.

17. Stevens GA, Bennett JE, Hennocq Q, Lu Y, De-Regil LM, Rogers L, Danaei G, Li G, White RA, Flaxman SR, Oehrle SP. Trends and mortality effects of vitamin A deficiency in children in 138 low-income and middle-income countries between 1991 and 2013: a pooled analysis of populationbased surveys. Lancet Glob Health 2015;3(9):e528-36.

18. Paine JA, Shipton CA, Chaggar S, Howells RM, Kennedy MJ, Vernon G, Wright SY, Hinchliffe E, Adams JL, Silverstone AL, Drake R. Improving the nutritional value of Golden Rice through increased pro-vitamin A content. Nat Biotechnol 2005;23(4):482.

19. Swamy BM, Samia M, Boncodin R, Marundan S, Rebong DB, Ordonio RL, Miranda RT, Rebong AT, Alibuyog AY, Adeva CC, Reinke R. Compositional analysis of genetically engineered GR2E "Golden Rice" in comparison to that of conventional rice. J Agricult Food Chem 2019;67(28):7986.

20. Bollinedi H, Dhakane-Lad J, Krishnan SG, Bhowmick PK, Prabhu KV, Singh NK, Singh AK. Kinetics of $\beta$-carotene degradation under different storage conditions in transgenic Golden Rice ${ }^{\circledR}$ lines. Food Chemistry 2019;278:773-9.

21. Office of Dietary Supplements. Vitamin A: Factsheet for Health professionals [Internet]. National Institutes of Health Office of Dietary Supplements. 2019.

22. Wilson A, Latham J. GMO golden rice offers no nutritional benefits says FDA. Independent Science News [Internet]. 2018 June 3. Available from: https://www.independentsciencenews.org/news/gmo-golden-rice-offers-no-nutritional-benefitssays-fda/

23. Vukovar. Agriculture in Nature and Environment Protection [Internet]. $11^{\text {th }}$ Scientific / professional conference on Agriculture in Nature and Environment Protection; May 28-30, 2018; Republic of Croatia. Osijek: Ivan Simic [2018 May 28-30]. Available from: http://www.hdpot.hr/images/files/Vukovar\%20zbornici/Vukovar\%20-\%20Zbornik\%202018.pdf

24. Bollinedi H, Prabhu KV, Singh NK, Mishra S, Khurana JP, Singh AK. Molecular and functional characterization of GR2-R1 event based backcross derived lines of golden rice in the genetic background of a mega rice variety Swarna. PloS One 2017;12(1):e0169600.

25. Then C. Data on 'Golden Rice' not sufficient to show health safety and indicate low benefits [Internet]. Testbiotech. IIIAB. 2018 Feb 5. Available from: https://www.testbiotech.org/en/news/data-golden-rice-not-sufficient-show-health-safety-andindicate-low-benefits

26. Testbiotech. GMO golden rice shows stunted and abnormal growth with reduced grain yield. GMWatch. 2017 Feb 16. Available from: https://gmwatch.org/en/news/latest-news/17470-gmogolden-rice-shows-stunted-and-abnormal-growth-with-reduced-grain-yield

27. Lu BR, Yang C. Gene flow from genetically modified rice to its wild relatives: Assessing potential ecological consequences. Biotechnol Adv 2009;27(6):1083-91.

28. Chikkappa GK, Tyagi NK, Venkatesh K, Ashish M, Prabhu KV, Mohapatra T, Singh AK. Analysis of transgene (s)(psy+ crtI) inheritance and its stability over generations in the genetic background of indica rice cultivar Swarna. J Plant Biochem Biotechnol 2011;20(1):29-38.

29. Batista R, Saibo N, Lourenço T, Oliveira MM. Microarray analyses reveal that plant mutagenesis may induce more transcriptomic changes than transgene insertion. Proc Natl Acad Sci 2008;105(9):3640-5.

30. Glenn KC. Nutritional and safety assessments of foods and feeds nutritionally improved through biotechnology: Lysine maize as a case study. Journal of AOAC International 2007;90(5):1470-9.

31. Finnegan J, McElroy D. Transgene inactivation: plants fight back!. Biotechnology. 1994;12(9):883. 
32. Schaub P, Al-Babili S, Drake R, Beyer P. Why is golden rice golden (yellow) instead of red?. Plant Physiol 2005;138(1):441-50.

33. Meyer P, Linn F, Heidmann I, Meyer H, Niedenhof I, Saedler H. Endogenous and environmental factors influence $35 \mathrm{~S}$ promoter methylation of a maize $\mathrm{A} 1$ gene construct in transgenic petunia and its colour phenotype. Mol Gen Genetics 1992;231(3):345-52.

34. Then C, Lorch A. A simple question in a complex environment: How much Bt toxin do genetically engineered MON810 maize plants actually produce. 2008) Implications of GM-Crop Cultivation at Large Spatial Scales., Theorie in der Ökologie. 2008;14.

35. Matthews D, Jones H, Gans P, Coates S, Smith LM. Toxic secondary metabolite production in genetically modified potatoes in response to stress. J Agricult Food Chem 2005;53(20):7766-76.

36. Zeller SL, Kalinina O, Brunner S, Keller B, Schmid B. Transgenex environment interactions in genetically modified wheat. PLoS One 2010;5(7):e11405.

37. Gertz JM, Vencill WR, Hill NS. Tolerance of transgenic soybean (Glycine max) to heat stress. In BRIGHTON CROP PROTECTION CONFERENCE WEEDS 1999 (Vol. 3, pp. 835-840).

38. Zeller SL, Kalinina O, Brunner S, Keller B, Schmid B. Transgenex environment interactions in genetically modified wheat. PLoS One 2010;5(7):e11405.

39. Then C, Potthof C. Risk Reloaded: Bericht zum Umgang mit den Risiken gentechnisch veranderter Pflanzen in der EU [Internet]. 2009 October. Munchen; Testbiotech. Available from: https://www.testbiotech.org/sites/default/files/risk-reloaded deutsch 4.pdf

40. Delouche J et al. Weedy rices- origin, biology, ecology, and control [Internet]. Food and Agricultural Organization of United Nations. 2007. Rome; FAO Plant Production and Protection Paper.

41. Chen LJ, Lee DS, Song ZP, Suh HS, LU BR. Gene flow from cultivated rice (Oryza sativa) to its weedy and wild relatives. Ann Botany 2004;93(1):67-73.

42. Xia H, Lu BR, Su J, Chen R, Rong J, Song Z, Wang F. Normal expression of insect-resistant transgene in progeny of common wild rice crossed with genetically modified rice: its implication in ecological biosafety assessment. Theoret Appl Genetics 2009;119(4):635-44.

43. Lu BR, Yang C. Gene flow from genetically modified rice to its wild relatives: Assessing potential ecological consequences. Biotechnol Adv 2009;27(6):1083-91.

44. Bauer-Panskus A, Breckling B, Hamberger S, Then C. Cultivation-independent establishment of genetically engineered plants in natural populations: current evidence and implications for EU regulation. Environmental Sciences Europe 2013;25(1):34-8.

45. Ziska LH, Bunce JA, Shimono H, Gealy DR, Baker JT, Newton PC, Reynolds MP, Jagadish KS, Zhu C, Howden M, Wilson LT. Food security and climate change: on the potential to adapt global crop production by active selection to rising atmospheric carbon dioxide. Proc Royal Soc B: Biol Sci 2012;279(1745):4097-105.

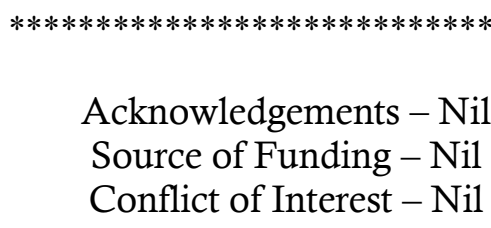

